researchers for various species (Butler and Loeffel 1972; Ebener and Copes 1982; Eames and Hino 1983)

Acknowledgments. - We thank K. Mills and R. A. Bodaly for useful criticisms of an earlier draft of this manuscript.

\section{References}

Arnason, A. N., C. R. Krasey, and K. H. Mills. 1982. A computer program for predicting precision and tag-loss bias in Jolly-Seber mark-recapture estimates. Canadian Technical Report of Fisheries and Aquatic Sciences 1083.

Arnason, A. N., and K. H. Mills. 1981. Bias and loss of precision due to tag loss in Jolly-Seber estimates for mark-recapture experiments. Canadian Journal of Fisheries and Aquatic Sciences 38:1077-1095.

Beamish, R. J. 1973. Design of a trapnet with interchangeable parts for the capture of large and small fishes from varying depths. Journal of the Fisheries Research Board of Canada. 30:587-590.

Beamish, R. J., L. M. Blouw, and G. A. McFarlane. 1976. A fish and chemical study of 109 lakes in the Experimental Lakes Area (ELA), northwestern Ontario, with appended reports on lake whitefish ageing errors and the northwestern Ontario baitfish industry. Canadian Fisheries and Marine Service Technical Report 607.

Beamish, R. J., and seven coauthors. 1983. A summary of sablefish tagging and biological studies conducted during 1980 and 1981 by the Pacific Biological Station. Canadian Manuscript Report of Fisheries and Aquatic Sciences 1732.

Butler, J. A., and R. E. Loeffel. 1972. Comparison of retention of anchor and spaghetti tags by salmon. Pacific Marine Fisheries Commission Bulletin 8:82.

Eames, M. J., and M. K. Hino. 1983. An evaluation of four tags suitable for marking juvenile chinook salmon. Transactions of the American Fisheries Society 112:464-468.

Ebener, M. P., and F. A. Copes. 1982. Loss of Floy anchor tags from lake whitefish. North American Journal of Fisheries Management 2:90-93.

Koshinsky, G. D. 1972. An evaluation of two tags with northern pike (Esox lucius). Journal of the Fisheries Research Board of Canada 29:469-476.

Moring, J. R., and K. A. Moring. 1976. Comparisons of returns of color-coded wire head tags and anchor tags in delayed-release chinook salmon. Progressive Fish-Culturist 38:200-202.

Myhre, R. J. 1966. Loss of tags from Pacific halibut as determined by double-tag experiments. International Pacific Halibut Commission Report 41.

White, W. J., and R. J. Beamish. 1972. A simple fish tag suitable for long-term marking experiments. Journal of the Fisheries Research Board of Canada 29:339-341.

Wydoski, R., and L. Emery. 1983. Tagging and marking. Pages $215-237$ in L. A. Nielsen and D. L. Johnson, editors. Fisheries techniques. American Fisheries Society, Bethesda, Maryland.

\title{
Preparation of Small Otoliths for Microscopic Examination
}

\author{
David L. Schultz and R. Scott Taylor \\ Department of Biology and \\ Museum of Zoology \\ University of Michigan \\ Ann Arbor, Michigan 48109, USA
}

Abstract. - We present a method for the preparation of small otoliths that consists of mounting otoliths in thin-section epoxy on an acetate sheet. After mounting, the otoliths can be handled easily during grinding, polishing, and microscopic observation. Mounting on acetate also allows for easy preparation of thin sections. We have found this technique to give satisfactory results and is more rapid than other published techniques.

It is well known that the otoliths of fishes provide a record of growth and age. This is due to a circadian deposition of differential amounts of protein in an aragonite matrix. The records of growth, age-specific size, and current age that otoliths provide make them potentially very useful for answering many questions about fish ecology and fisheries management (for a recent review of otolith structure and potential applications in fish biology, see Campana and Neilson 1985). However, with current preparation techniques, the utility of otoliths is restricted to questions that require relatively small numbers of otoliths for answers because of the time and labor involved in preparation prior to analysis. This problem is compounded if otoliths from small species or young individuals are used because these cause a handling problem as well. We present a method for preparation of small otoliths $(0.5-2.0 \mathrm{~mm}$ diameter) that decreases the amount of time involved 
and maintains a good deal of flexibility in the ultimate usage of the otoliths.

Fish have three pairs of otoliths; in order of decreasing size, they are the sagittae, lapilli, and asterisci. The sagitta is commonly used for examination of growth increments, but the lapillus is also used. With the sagitta, examination of a large series of growth increments that includes the nucleus requires preparation of sections that are perpendicular to the broadest surface and along the long axis, as described by Pannella (1980). The regular growth of the lapillus allows observation of such series more easily with sections of the broadest surface. The technique to be described is best suited for preparation of one surface of the lapillus for observation with a light or scanning electron microscope, but it can be used for preparation of the sagitta as well; the technique can also be easily modified for the preparation of thin sections.

After otoliths are removed, they must be cleaned of any tissue. If the otoliths can be seen with the naked eye, they can be cleaned effectively by rubbing them between the fingers. If they are too small for this, a dissecting microscope, jewelers forceps, and dissecting needles must be used. Freezing the otoliths in water prior to cleaning can aid in the removal of surrounding tissue. We have found it best to keep otoliths in water, as they fracture more easily once they have been allowed to dry.

The principal problem with small otoliths is handling them during preparation. We have found that handling problems can be minimized by mounting the otoliths in a droplet of epoxy on a small sheet of acetate. The acetate-mounted otolith can be handled easily and the slide can be labeled with a permanent marker if necessary. We have used acetate sheet of the type used for overhead transparencies cut to approximately $2 \times 7$ $\mathrm{cm}$. The otolith is mounted near one end of this sheet. We use Hillquist thin-section epoxy type A-B (Hillquist, 1545 Northwest 49th Street, Seattle, Washington 98107) for mounting. This epoxy cures at $80^{\circ} \mathrm{C}$ in $30 \mathrm{~min}$ and is often used for the preparation of geological thin sections. It is hard once cured, and we have found that otoliths can be mounted in this medium after blot drying or a few minutes of air drying. Only sufficient epoxy to hold the otolith in place on the acetate is required, but a broadly spread drop minimizes lateral movement of the otolith during grinding and thus ensures a planar grind. The otolith is imbedded in the epoxy with the surface to be ground upwards and the opposite surface pushed flush against the acetate. The epoxy holds the otolith to the relatively flat acetate sheet, which allows grinding of a flatter section than could be obtained without mounting.

We have found that grinding of the otolith is easily and quickly accomplished with adhesive, glass-mounted, 600-grit, wet silicon carbide paper (source: Mager Scientific Incorporated, Dexter, Michigan 48130). If excessive amounts of epoxy are used, 400-grit paper may be used to remove this to the surface of the otolith. The otolith is held under the tip of the index finger and the remaining acetate strip is held between the thumb and index finger. Grinding is done by stroking the otolith over the paper. A nonbeveled section is ensured with alternate strokes, each at $90^{\circ}$ to the previous stroke. Grinding should be done with minimum pressure to avoid fracturing the otolith. Of course, care must be taken to not grind through the nucleus, and regular light microscopic observation should accompany grinding. After perinuclear increments can be seen, their clarity can be improved by one of two means. (1) High-speed lapidary polishing of the otolith with $0.05-\mu \mathrm{m}$ aluminum oxide (source: Mager Scientific) provides a surface free of scratches and a clearer view of increments with light microscope. (2) Alternatively, we have found that flooding the surface with an oil of a suitable refractive index, such as clove oil or oil of wintergreen, often allows clear observation of the increments without polishing. Radtke and Dean (1982) reported that immersion oil also may aid in clearing of the otolith. If acetate impressions are to be made or a scanning electron microscope is to be used for observation, then grinding to the plane of the nucleus is required, followed by high-speed polishing and etching with a weak acid.

This technique allows relatively easy preparation of double-ground thin sections. After one surface is ground to near the plane of the nucleus, the epoxy that holds the otolith can be cut from the remainder of the acetate sheet with scissors and the otolith can be turned over and mounted with epoxy on another piece of acetate. The original acetate can then be ground away with 400-grit paper. Once the acetate is removed, the epoxymounted otolith can be ground to a very thin section. This can provide a better resolution of growth increments with a light microscope than a singleground section.

Other techniques for the preparation of otoliths have been described (Brothers et al. 1976; Neilson and Geen 1981; Campana and Neilson 1982). 
These call for mounting the otolith on a glass slide with an adhesive or for hand-held grinding of large otoliths (Brothers et al. 1976). Small otoliths are not easily ground by hand and must be mounted. Mounting on glass slides requires, for many media, that the glass be preground to allow bonding between the medium and glass. This adds an additional step that is not required with the acetate sheets. We have found the grinding and polishing process to be more difficult with glass slides without the use of an apparatus for holding the slide. The acetate-mounted otolith, however, is easily held for grinding and polishing. If a gig is to be used for grinding (Neilson and Geen 1981), the acetate-mounted otolith could be affixed to the plate held by the gig with a temporary cement.

We have found that this technique allows relatively rapid preparation of otoliths. Once a routine is established, the average preparation time of an otolith is less than 10 min. Thus, a large number of specimens may be prepared in $1 \mathrm{~d}$.

Acknowledgment. - Dan Fisher aided in the development of this method and donated much of the material used for the many modifications attempted.

\section{References}

Brothers, E. B., C. P. Mathews, and R. Lasker. 1976. Daily growth increments in otoliths from larval and adult fishes. U.S. National Marine Fisheries Service Fishery Bulletin 74:1-8.

Campana, S. E., and J. D. Neilson. 1982. Daily growth increments in otoliths of starry flounder, Platichthys stellatus, and the influence of some environmental variables in their production. Canadian Journal of Fisheries and Aquatic Sciences 39:937-942.

Campana, S. E., and J. D. Neilson. 1985. Microstructure of fish otoliths. Canadian Journal of Fisheries and Aquatic Sciences 42:1014-1032.

Neilson, J. D., and G. H. Geen. 1981. Method for preparing otoliths for microstructure examination. Progressive Fish-Culturist 43:90-91.

Pannella, G. 1980. Growth patterns in fish sagittae. Pages 519-560 in D. C. Rhoads and R. A. Lutz, editors. Skeletal growth of aquatic organisms. Plenum, New York.

Radtke, R. L., and J. M. Dean. 1982. Increment formation in the otoliths of embryos, larvae and juveniles of the mummichog, Fundulus heteroclitus. U.S. National Marine Fisheries Service Fishery Bulletin 80:201-215. 